\title{
A escola e a igualdade de oportunidades: alguns apontamentos para a reflexão
}

\author{
School and equal opportunities: some points for reflection \\ La escuela y la igualdad de oportunidades: algunos apuntamientos para la reflexión
}

Recebido: 25/08/2021 | Revisado: 30/08/2021 | Aceito: 02/09/2021 | Publicado: 05/09/2021

Gilberto Oliari

ORCID: https://orcid.org/0000-0003-3102-8383 Universidade Comunitária da Região de Chapecó, Brasil E-mail: gilba@unochapeco.edu.br

\begin{abstract}
Resumo
A pergunta que move esse texto é: "Como a escola pode promover igualdade de oportunidades para as crianças e jovens?" Para respondê-la, dialogamos (de modo teórico bibliográfico) com alguns filósofos da educação escolar. Partimos do pressuposto de que todos os alunos têm capacidades próprias para aprender o que se ensina na escola - a matéria - e, por isso, abordamos que a igualdade deve ser um princípio pedagógico. Para exemplificar a experiência da igualdade de inteligências na educação apresentamos dois modos de ser mestre que busca emancipação intelectual dos alunos: o mestre ignorante e o mestre inventor.
\end{abstract}

Palavras-chave: Educação; Escola; Igualdade de inteligências.

\begin{abstract}
The question that moves this text is "How can school promote equal opportunities for children and adolescents?" In order to answer this question, we dialogue (bibliographically theoretical) with some philosophers of school education. We start from the assumption that all students have their own abilities to learn what is taught in school - the subject and, therefore, we approach that equality must be a pedagogical principle. In order to exemplify the experience of the equality of intelligences in education we present two ways of being a teacher that seeks the intellectual emancipation of students: the ignorant teacher and the inventor teacher.
\end{abstract}

Keywords: Education; School; Equality of intelligences.

\section{Resumen}

La pregunta que mueve ese texto es: ¿Cómo la escuela puede promover la igualdad de oportunidades a los niños y a los jóvenes?" Para contestar charlamos (bibliográficamente teórico) con algunos filósofos de la educación escolar. Partímos del presupuesto de que todos los alumnos tienen capacidades propias para aprender lo que se enseña en la escuela - la materia - y, por eso, abordamos que la igualdad debe ser un principio pedagógico. Para ejemplificar la experiencia de la igualdad de inteligéncias en la educación presentamos dos maneras de ser maestro que busca la emancipación intelectual de los alumnos: el maestro ignorante y el maestro inventor.

Palabras clave: Educación; Escuela; Igualdad de inteligéncias.

\section{Introdução}

Há, no tempo presente, muitas ideias políticas e ações que visam domesticar a escola e submetê-la à interesses externos à sua tarefa primordial: apresentar como o mundo funciona para as gerações de recém-chegados. Masschelein e Simons (2017) apresentam seis formas de domesticação da escola: politização, pedagogização, naturalização, tecnologização, psicologização e popularização. Focamos nossas reflexões, neste artigo, na problematização do aspecto da naturalização, que diz respeito às “diferenças de inteligência ou diferenças de capacidade” dos estudantes, (Masschelein \& Simons, 2017, p. 116) como princípios para a seleção do que deverá ser apresentado a ele/a. Buscamos problematizar esta forma de domesticação argumentando que a escola deve ser um espaço aberto e democrático, possibilitando a todos a manifestação das inteligências.

A naturalização das desigualdades tem ganhado centralidade na contemporaneidade, quando em políticas reformistas educacionais se afirma que os processos educativos devem pautar-se no desenvolvimento dos talentos, de habilidades ou de competências dos alunos. Talento é entendido "[...] como um conceito [que] se refere a diferenças na predisposição entre alunos" (Masschelein \& Simons, 2017, p. 117). Também, desenvolver um talento implica na sua efetiva e eficiente transformação “[...] 
em competências e qualificações que maximizam a empregabilidade dos jovens" (Masschelein \& Simons, 2017, p. 118). Assim, naturalizar as diferenças é perpetuar um modo de ser da própria sociedade, no qual os saberes também são hierarquizados e assalariados de acordo com as demandas do mercado.

Buscaremos, então, refletir filosoficamente sobre a responsabilidade de a escola ser um espaço de criação de igualdade de oportunidades para todos os alunos inserirem-se no mundo comum. Bem como, nos propomos a apresentar um conjunto de apontamentos e questionamentos relativos a igualdade de oportunidade a ser desenvolvida na escola, destacando alguns conceitos, que nos permitem chamar atenção para um modo democrático de desenvolvimento do escolar, ou seja, daquilo que ocorre em sala de aula, na relação entre professor e alunos, a partir do algo que se quer ensinar.

Como Masschelein e Simons (2017, p. 72), partimos da premissa que "[...] cada aluno, independentemente de seus antecedentes ou talento natural, tem capacidade de se tornar interessado em alguma coisa e se desenvolver de maneira significativa". Desse modo, refletir sobre a escola é problematizar as possibilidades de efetivar o princípio de que todos os alunos possuem capacidades para conhecer o mundo e inserir-se nele, independe do seu modo pessoal de conhecer e relacionar-se com ele.

A pergunta que orienta nosso percurso reflexivo apresenta-se da seguinte forma: como a escola pode promover igualdade de oportunidade às crianças e jovens que cotidianamente estão em suas salas de aulas? Compreendemos a igualdade como um princípio pedagógico da escola (Masschelein \& Simons, 2017), que de alguma forma consegue estabelecer uma comunidade educacional (Biesta, 2013) entre alunos e professores, com o objetivo de inserir a nova geração no mundo comum (Arendt, 2008).

A igualdade “[...] exige que se parta, não do que o 'ignorante' desconhece, mas do que sabe. $\mathrm{O}$ ignorante sempre sabe alguma coisa e sempre pode relacionar o que ignora ao que já sabe" (Vermeren et al., 2003, p. 191). Desse modo caberia à escola, com maior ênfase, verificar se a igualdade de inteligências está sendo fomentada nas diferentes práticas pedagógicas e se há possibilidade de os alunos inserirem-se no mundo comum do conhecimento com suas inteligências.

Com Hannah Arendt, (2008, p. 31), compreendemos que "[...] todas as atividades humanas são condicionadas pelo fato de que os homens vivem juntos". O fato de vivermos juntos estabelece um mundo comum, o qual "[...] adentramos ao nascer e que deixamos para trás quando morremos. Transcende a duração de nossa vida [...]: preexistia à nossa chegada e sobreviverá à nossa breve permanência" (Arendt, 2008, p. 65). Constitui-se, assim, uma grande comunidade, a partir da relação entre os que já passaram, os que estão e os que virão ao mundo. O fato de vivermos juntos estabelece um mundo comum.

Essa inserção no mundo comum acontece através das ações e do discurso, pois são esses "[...] os modos pelos quais os seres humanos se manifestam uns aos outros, não como meros objetos físicos, mas enquanto homens" (Arendt, 2008, p. 189). Inserir-se no mundo significa revelar sua identidade através dos discursos a outros seres humanos e "[...] tomar iniciativa, iniciar [...] imprimir movimento a alguma coisa" (Arendt, 2008, p. 190). Para haver essa inserção no mundo é necessário que a escola promova a formação de comunidades, pautadas na igualdade de oportunidades, através do oferecimento da cultura acumulada, dos conhecimentos para a nova geração. A escola, então, deve assumir-se como uma "[...] instituição educativa democrática e de qualidade socialmente referenciada, [e garantindo] o acesso ao conhecimento e ao patrimônio cultural historicamente produzido" (Cruz \& Agudo, 2018, p. 88).

Organizamos este texto em três momentos: no primeiro abordamos o princípio de igualdade como um elemento pedagógico da escola e sustentamos que todos os alunos têm potencial para inserirem-se no mundo dos conhecimentos abordados nela. No segundo momento exploramos as condições escolares para a igualdade de oportunidades, apontando os elementos que constituem o escolar, de acordo com Masschelein e Simons (2017). Por fim, apresentamos nossa reflexão sobre dois modos de criar igualdade de oportunidade: o ignorante e o inventor e apontamos alguns aspectos da vida de dois professores que, em seu tempo e em seu espaço, puderam ensaiar-se criando escolas que potencializaram a capacidade intelectual de todos os alunos. 


\section{Sobre o Princípio de Igualdade como um Elemento Pedagógico da Escola}

Podemos dizer que a escola é uma invenção histórica criada para introduzir crianças e jovens no mundo. É o lugar onde “[...] os jovens (de acordo com um método específico) são abastecidos com tudo o que eles devem aprender para encontrar o seu lugar" (Masschelein \& Simons, 2017, p. 25). Sendo assim, a escola é um lugar próprio onde se transmite os conhecimentos histórica e socialmente construídos para as gerações que vão chegando ao mundo comum. No entanto, essa transmissão não pode ser fechada em si mesma; ela deve ser aberta, de modo que o aluno que está recebendo os conhecimentos possa ressignificá-lo a seu modo, produzindo suas compreensões.

De acordo com Masschelein e Simons, (2017, p. 26), é importante ressaltar que a escola é uma invenção (política) específica da pólis grega. A escola grega surgiu como uma usurpação do privilégio das elites aristocráticas e militares da Grécia antiga. Desse modo, um dos princípios da escola, em sua gênese grega, é oferecer oportunidade de acesso aos conhecimentos àqueles que antes não tinham nenhum espaço público para fazê-lo. Nesse sentido, “[...] o mais importante ato que a 'escola faz' diz respeito à suspensão de uma chamada ordem desigual natural” (Masschelein \& Simons, 2017, p. 26). A escola estabeleceu, assim, “[...] um tempo e espaço que estava, em certo sentido, separado do tempo e espaço tanto da sociedade [...] quanto da família" (Masschelein \& Simons, 2017, p. 26).

A escola pode ser considerada como um espaço onde os estudantes podem suspender seus antecedentes familiares e sociais e criar tempo para o aprendizado das coisas do mundo. Estabelece, dessa forma, uma democratização do tempo livre, ao chamar atenção para os conhecimentos em si mesmos e não para sua possível utilidade. O tempo livre pode ser entendido como um tempo disponibilizado em um espaço - a escola - que potencializa ao estudante "[...] sair de seu ambiente conhecido, para se superar e renovar (e, portanto, mudar de forma imprevisível) o mundo" (Masschelein \& Simons, 2017, p. 10). Os diferentes componentes curriculares (disciplinas, matérias) da escola cumprem, por conseguinte, a tarefa de contribuir para que o aluno saia do seu mundo conhecido (dos fatos corriqueiros do cotidiano) para adentrarem nos mundos específicos do conhecimento, das teorias, das artes, da literatura, etc.

A ideia de que a escola pode gerar igualdade de oportunidade há anos é refutada, geralmente afirma-se que a escola reproduz desigualdades sociais através de sua estrutura e organização, que ela não gera empregabilidade, etc. Esses são argumentos que nos contrapomos, acompanhados de Masschelein e Simons (2017, p. 68), pois “[...] talvez não haja nenhuma invenção humana mais habilitada em criar igualdade do que a escola”. São inúmeras as crônicas, os contos, as histórias e os filmes a demonstrar que a escola e os professores podem ser "[...] agentes capazes de ajudar os alunos a escaparem de seu mundo da vida" (Masschelein \& Simons, 2017, p. 68). Conforme os autores, o campo cinematográfico tem nos brindado com roteiros que apresentam a escola e professores como referências fundamentais para que jovens e/ou crianças encontrem outros sentidos de sua existência.

Podemos até citar alguns desses: o filme "Escritores da Liberdade" (LaGravenese, 2007) que mostra a transformação realizada na vida de jovens de periferia dos Estados Unidos da América, a partir de experiências de valorização de suas inteligências e de suas subjetividades; o filme "Como estrelas na Terra" (Khan, 2007) que apresenta a busca por oportunizar espaços, em uma escola da Índia, onde 'alunos diferentes' pudessem se expressar e encontrar seu lugar no mundo a partir da experiência escolar. E, tantos outros que demonstram o quanto é possível e necessário, criar espaços nos quais os alunos possam revelar suas identidades e seus conhecimentos.

A escola pode, pois, interromper ciclos de vida viciosos, oportunizando o aluno vislumbrar outras possibilidades de inserção no mundo, que vão (ou podem ir) muito além de seus mundos privados. Por isso, “[...] a escola, nesse sentido, sempre tem a ver com a experiência de potencialidade" (Masschelein \& Simons, 2017, p. 69), ou seja, as práticas escolares podem estar muito mais relacionadas com o que o aluno pode vir a ser, do que o que o aluno é no seu momento escolar. Independentemente de classe social, gênero e de etnia, todo aluno deve ser considerado como 'capaz de...'. 
Masschelein e Simons (2017) dizem que a suspensão, a profanação, a atenção ao mundo e as tecnologias escolares (como veremos detidamente na próxima parte do texto) fazem com que a escola seja geradora de oportunidade de igualdade. A escola, como skholé, tempo livre, realiza a 'liberação' dos conteúdos das amarras produtivistas e econômicas; de pressupostos utilitaristas dos conhecimentos e de que para conhecer não é necessário ter disciplina, nem organização e, muito menos, se utilizar de tecnologias específicas.

É também da ordem do escolar a tarefa de criar comunidades; de criar grupos de pessoas que partilham de objetivos comuns. As maiores comunidades estabelecidas na escola são as comunidades dos alunos (embora exista a dos professores e dos outros servidores - equipe pedagógica, direção, profissionais de limpeza, etc.). Mesmo que haja diferenças entre os alunos em sala de aula "[...] por se concentrarem no que é oferecido, essas diferenças são (temporariamente) suspensas e uma comunidade é formada com base na participação conjunta" (Masschelein \& Simons, 2017, p. 85). Por isso, é que podemos afirmar que cada turma pode formar uma comunidade que é única, pois possui especificidades e singularidades; nenhuma turma (comunidade) é igual à outra.

O filósofo da educação Gert Biesta, (2013), reflete, também, sobre a formação das comunidades na escola, apontando que essas, criam uma linguagem e uma estrutura conceitual comum, delimitando fronteiras entre elas. Ele apresenta dois tipos de comunidades que se estabelecem, (produzem-se ou são produzidas), nas escolas: as comunidades racionais e as comunidades educacionais. Embora o elo entre os alunos seja a linguagem, essas comunidades se diferenciam, como veremos a seguir..

As comunidades racionais “[...] nos capacitam a falar, mas apenas na linguagem e na lógica dessa comunidade. Embora importe certamente o que dizemos, não importa quem está dizendo" (Biesta, 2013, p. 89). Cria-se, pois, nessas comunidades há um conjunto próprio de conceitos e os atos de fala, que são posteriormente reproduzidos em diferentes circunstâncias; após um conhecimento ser criado é apenas reproduzido, não há possibilidade de ser revisto, repensado ou ressignificado, torna-se quase um dogma a ser perpetuado de forma idêntica, linearmente para todos. As pessoas que falam são intercambiáveis, pois não importa quem elas são e, sim, o que elas dizem. E, só podem dizer o que passa na comunidade, "[...] tornando-se membro" (Biesta, 2013, p. 87) dela, ou seja, não é permitido que haja apropriação de conceitos de comunidades que não seja a sua.

Essas comunidades racionais, são formadas por indivíduos que associam-se a discursos de caráter normativo universal. Nas considerações de Biesta (2013, p. 82) “[...] esperamos de médicos, veterinários ou eletricistas que falem de acordo com as regras e princípios do discurso racional da comunidade da qual são um representante", portanto a universidade do discurso permite que apenas os conceitos e ideias que estão dentro desse círculo sejam proferidas. Esse modo de estabelecer uma comunidade racional, não permite que haja uma igualdade de oportunidades, pois "[...] ao falar com a voz da comunidade racional, não sou realmente eu quem está falando" (Biesta, 2013, p. 92).

$\mathrm{E}$, ter oportunidade igual, de acordo com nossa reflexão, significa poder expressar o seu modo de pensar, a sua forma de compreender o mundo, que não implica necessariamente estar ligada a uma comunidade racional específica, por isso nos propomos a refletir criticamente a construção relacional dessas comunidades, problematizando um pressuposto e apresentando, juntamente a Biesta (2013) outra comunidade possível e necessária para a igualdade de oportunidades na escola.

Podemos pensar que a linguagem das comunidades racionais é mera fabricação, pois não visam a revelação dos sujeitos que estão falando. Segundo Arendt (2008, p. 193), “[...] sem a revelação do agente no ato, a ação perde seu caráter específico e torna-se um feito como outro qualquer". Por isso, é necessário pensar na criação de outras comunidades possíveis. As comunidades educacionais (Biesta, 2013), podem ser mais potentes para nossa reflexão. Pois as comunidades educacionais tendem a oportunizar espaços onde seja possível encontrar e enfrentar "[...] o que é diferente, estranho e outro, e também que existam oportunidades para nossos estudantes responderem, encontrarem sua própria voz, seu próprio modo de falar" (Biesta, 2013, p. 98) 
A construção de comunidades educacionais permite considerar que, nelas os sujeitos podem se posicionar, do seu modo, sobre os conhecimentos, importando de forma significativa o 'quem' está falando. Pois, para haver igualdade de oportunidade, torna-se fundamental reconhecer a subjetividade das pessoas envolvidas no processo educativo. Tal subjetividade refere-se ao aprendizado. O aprendizado é uma reação, uma resposta a uma pergunta, que segundo Biesta (2013, p. 97):

Se consideramos a aprendizagem dessa maneira, podemos dizer que alguém aprendeu alguma coisa não quando foi capaz de copiar e reproduzir o que já existia, mas quando alguém responde ao que não é familiar, ao que é diferente, ao que desafia, irrita ou até perturba. Então a aprendizagem se torna uma criação ou uma invenção, um processo de introduzir algo novo no mundo: a resposta única de alguém.

Essa possibilidade de aprender, como alguém que pode posicionar-se e apresentar seu modo único de exposição ao mundo, é ser considerado como 'capaz de...'; é sentir, em si mesmo, o princípio da igualdade de oportunidade, ou, em outras palavras, tornar-se presença no mundo. O que importa não é a reprodução de conteúdos ou a formação de comunidades racionais com discursos universais, mas a formação de comunidades educacionais, nas quais é possível tomar outros caminhos que não foram traçados anteriormente, com responsabilidade ética sobre o que se faz.

Podemos sintetizar da seguinte forma: nas comunidades racionais, há apenas reprodução de conhecimentos universais, não importa o quem está proferindo o conhecimento e, sim o que está sendo proferido. Já nas comunidades educacionais, o quem está falando adquire outra ordem, ele subjaz o que está sendo dito; de outro modo, nas comunidades educacionais não há mera reprodução, todos são chamados a proferir seus conhecimentos e apresentá-los do modo como conhece e interpreta as coisas e os fenômenos do mundo.

\section{Das Condições Escolares para a Igualdade de Oportunidades}

Há em Masschelein e Simons (2017) uma compreensão de que a escola é um local onde há tempo livre (skholé) - tempo não produtivo, não econômico, para que todos estudem e aprendam.

A escola oferece o formato (ou seja, composição particular de tempo, espaço e matéria, que compõe o escolar) para o tempo-feito-livre, e aqueles que nele habitam transcendem a ordem social (econômica e política) e suas posições (desiguais) associadas. E é esse formato de tempo livre que constitui a ligação comum entre a escola dos atenienses livres e a coleção heterogênea das instituições escolares (faculdades, escolas secundárias, escolas primárias, escolas técnicas, escolas vocacionais, etc.) da nossa época (Masschelein \& Simons, 2017, p. 29).

O tempo escolar é um tempo cíclico e não linear, como na sociedade do trabalho produtivo. Há, na escola tempo para ler, pensar, escrever, debater, exercitar-se, correr e brincar. Esse tempo foge da lógica produtivista; na escola se pode 'perder tempo' pensando, estabelecendo diferentes relações, ensaiando-se no mundo. Acontece em ciclos: tem um horário para começar a aula e um horário para terminar; tem uma divisão em bimestres, trimestres ou semestres; há um calendário a ser seguido. O que acontece nesse intervalo (do dia, do mês, do ano) é (ou deve ser) o exercício do tempo livre para estudar a matéria disponibilizada pelo professor.

Mas, afinal, o que faz com que uma escola seja uma escola? Qual é o formato dessa instituição? Quais são os elementos que permitem distingui-la de outras instituições? São esses questionamentos que buscaremos responder nos parágrafos que seguem, observando um conjunto de oito elementos que formam o escolar, na perspectiva de Masschelein e Simons (2017).

Ao entrar na escola, o aluno pode ser liberado de seus antecedentes para se tornar um aluno entre tantos; isso significa dizer que na escola ocorre a suspensão. Suspender significa libertar, destacar, colocar entre parênteses (Masschelein \& Simons, 2017, p. 30). Suspende-se nesse espaço a correria do mundo do trabalho, orientada pelo produtivismo econômico. Na escola os 
estudantes dedicam-se ao estudo daquilo que é o objeto do estudo, conhecimentos, práticas, habilidades, separadamente de seu uso social e convencional; as coisas e fenômenos do mundo tornam-se matéria de aprendizado. "A escola e o professor permitem que os jovens reflitam sobre si mesmos, separados do contexto (antecedentes, inteligência, talentos, etc.) que os conecta a um determinado caminho" (Masschelein \& Simons, 2017, p. 34). Constitui-se, desta forma, uma brecha no tempo linear, que permite que os estudantes encontrem o seu lugar no mundo. No tempo livre, proporcionado pela escola, é possível que o aluno desenvolva a capacidade de se transformar, modelando-se em outro, pela suspensão de seu contexto.

$\mathrm{Na}$ escola deve acontecer também a profanação, ou o ato de tornar algo disponível, como um bem público. Para Masschelein e Simons (2017, p. 39) “[...]um tempo e um lugar profanos, mas também as coisas profanas referem-se a algo que é desligado do seu uso habitual [...] acessível a todos e sujeito a (re) apropriação de significado". A tarefa é, portanto, profanar: retirar da matéria o seu significado específico e torná-lo público, acessível ao uso de todos. Os assuntos abordados na escola são da sociedade, ou de diferentes instituições, mas na escola são profanados, são estudados em si mesmos. Profanar, na escola, é transformar algo em matéria de estudo, que é desvinculado de significações e de usos comuns, já legitimados.

A matéria de estudo, na escola, renova continuamente os sentidos e significados das coisas. Profanar rompe com dogmatismos; possibilita que compreensões e explicações sejam revistas, atualizadas e ressignificadas de acordo com a potencialidade daqueles que estão estudando. Profanar retira os conhecimentos da naturalização epistemológica, a qual separa os conhecimentos para os 'mais' ou 'menos' capazes.

O terceiro elemento fundamental, que diz daquilo que acontece na escola, na visão dos autores, refere-se a uma questão de atenção e de mundo, ou de abrir, criar interesse, trazer à vida, formar. (Masschelein \& Simons, 2017, p. 43). "A escola focaliza a nossa atenção em algo [...] infunde na nova geração uma atenção para com o mundo: as coisas começam a falar (conosco). [...] Trata-se do momento mágico quando alguma coisa, fora de nós mesmos, nos faz pensar [...]" (Masschelein \& Simons, 2017, p. 51). Essa chamada de atenção para o mundo é possível desde que haja uma abertura do mundo, criando interesse por aquilo que está fora de nós mesmos e nos faz pensar. Aquilo que antes não fazia parte do mundo do aluno, pelo interesse e pela atenção começa fazer; algo "[...] toca e nos leva a estudar, pensar e praticar" (Masschelein \& Simons, 2017, p. 52).

A fim de realizar a suspensão, a profanação e chamar atenção para as matérias, a escola atua com tecnologias. Para Masschelein e Simons, (2017, p. 52), a questão da tecnologia diz respeito a praticar, estudar, e, também, à disciplina. Curiosidade e interesse geram trabalho, que necessita de tecnologias escolares. A tecnologia é descrita de modo muito simples pelos autores: quadro, giz, papel, caneta, livro, assim como a carteira e a cadeira da sala de aula. Esses instrumentos têm como objetivo criar a disciplina na aula: “[...] sentar em uma carteira não é apenas estado físico; isso também acalma e focaliza atenção [...] a lousa mantém o professor com os pés no chão" (Masschelein \& Simons, 2017, p. 55).

Os métodos de ensino também podem ser considerados como tecnologias, de modo que "[...] tempo, espaço e recursos são organizados para tornar possível a experiência do ponto de partida e o evento de encontro" (Masschelein \& Simons, 2017, p. 58). Os autores citam alguns exemplos: o ditado, que retira a função inicial das palavras e transforma-as em um jogo de aprendizado; a escrita, que possibilita os alunos ensaiarem-se, dando forma a algo e a si mesmo; os exames, que exercem uma pressão necessária, ao produzir uma disciplina para o estudo.

A autoridade e a disciplina são elementos fundamentais da escola, pois “[...] deixar seu próprio mundo da vida e elevarse acima de si mesmo requer um esforço sustentado, facilitado por respeitar as regras" (Masschelein \& Simons, 2017, p. 65). As regras visam focalizar a atenção dos estudantes, minimizar sua distração e manter (quando necessário) o silêncio, a fim de que o exercício do aprendizado seja possível. Dessa forma, as tecnologias escolares são ajustadas "[...] para tornar possível o tempo livre. [...] permite o próprio 'ser capaz' ou que faz a experiência do 'posso fazer isso/ sou capaz"' (Masschelein \& Simons, 2017, p. 65). 
Uma questão de igualdade, ou ser capaz de começar, é o quinto elemento fundante da escola defendida por Masschelein e Simons (2017, p. 66). Diz respeito ao reconhecimento de que todos os alunos possuem igual capacidade e, por isso, a escola e os professores oferecem a oportunidade de iniciar algo. Sabemos que os alunos possuem suas particularidades, suas culturas diferentes, mas é importante que continuemos a acreditar no potencial de cada singularidade: “[...] a escola, nesse sentido, sempre tem a ver com a experiência da potencialidade" (Masschelein \& Simons, 2017, p. 69). Não se trata de legitimar as diferenças baseadas em aspectos naturais de desenvolvimento, condições sociais ou oportunidades; trata-se de rechaçar essa ideia e admitir que todos, sem exceção, podem estudar e conhecer. A escola é, pois, “[...] um tipo de vácuo no qual é dado tempo aos jovens e aos alunos para praticarem e se desenvolverem" (Masschelein \& Simons, 2017, p. 73)

O sexto elemento, proposto por Masschelein e Simons (2017, p. 73), é uma questão de amor, ou amateurismo, paixão, presença e mestria. Sabe-se hoje que o professor é considerado um especialista, alguém cuja experiência metódica e competente baseia-se nos conhecimentos científicos, porém de acordo com os autores há mais que conhecimentos, há que ser considerado o amor. "Um professor é alguém que ama seu tema ou matéria, que se preocupa com ela e presta atenção a ela. É um amor que se revela em pequenos gestos ordinários, em certos modos de falar e de escutar" (Masschelein \& Simons, 2017, pp. 76-77). Não é um amor ingênuo; é uma amorosidade que o faz preocupar-se com os princípios de abertura e de profanação do mundo a todos, para que possam aprender.

Como reconhecemos o professor amateur? Simplificando, isso é revelado por meio da extensão em que uma pessoa está presente no que faz e na forma como demonstra quem ela é e o que representa através de suas palavras e ações. Isso é o que se poderia chamar de mestria de um professor. Enquanto o conhecimento e a competência garantem um tipo de experiência, é a presença, o cuidado e a dedicação que dão expressão à mestria do professor. Ele personifica a matéria de uma determinada maneira e tem presença na sala de aula (Masschelein \& Simons, 2017, p. 78).

Pode-se dizer que o amor denota uma presença; uma presença pedagógica. O professor que ama sua matéria e seus alunos é capaz de personificar, de dar forma aos conteúdos e prender os alunos em sua paixão pelo conhecimento, pois “[...] é precisamente a mestria e o engajamento interessado e inspirado por parte do professor magistral que lhe permite inspirar e envolver os alunos" (idem, p. 80). Esse envolvimento não é convencimento ou doutrinação; é uma forma disciplinada de ensinar os alunos as matérias que ama e domina.

O professor que ama, coloca o foco sobre todos os alunos, pois é um amor "[...] que se expressa na abertura e compartilhamento do mundo" (Masschelein \& Simons, 2017, pp. 83 - 84). Não há privilegiados; todos têm igual capacidade para inserir-se no mundo. Por isso é que "[...] o professor amoroso não permite que os alunos se escondam por trás de fracassos ou inépcia que contam sobre si mesmos ou os outros contam sobre ele" (Masschelein \& Simons, 2017, p. 84).

Há também outro elemento: uma questão de preparação, ou estar em forma, ser bem treinado, ser bem-educado, testar os limites (Masschelein \& Simons, 2017, p. 86), assim eles propõem uma compreensão de que "[...] estudar é uma forma de aprender em que não se sabe, antecipadamente, o que pode ou se vai aprender; é um evento aberto que não tem 'função". Nesse sentido a preparação é considerar "[...] o conhecimento pelo bem do conhecimento, e habilidades pelo bem das habilidades, sem uma orientação específica, ou um destino definido" (Masschelein \& Simons, 2017, p. 92). Desse modo, a formação pretendida pela escola é um evento aberto; é pura preparação, sem destinos certos ou errados para os alunos percorrerem.

E, finalmente, uma questão de responsabilidade pedagógica, ou exercer autoridade, trazer à vida, trazer para o mundo. Refere-se ao significado pedagógico da escola. A questão pedagógica diz do "[...] abrir o mundo e trazer o mundo (palavras, coisas e práticas) que o compõem para a vida" (Masschelein \& Simons, 2017, p. 98). Dessa forma os alunos experimentam um envolvimento com o mundo e podem "perceber não apenas que têm que se iniciar no mundo, mas também que são capazes de 
começar" (Masschelein \& Simons, 2017, p. 99). Essa é a responsabilidade do professor, apresentar o mundo de forma aberta para os alunos, para que eles possam encontrar o seu modo de inserir-se nele.

A responsabilidade se traduz em duas tarefas: primeira, "[...] o professor deve libertar a criança de todas as habilidades que atribuem uma função imediata, explicação ou destino para o que essa criança faz" (Masschelein \& Simons, 2017, p. 101). A segunda: "[...] estimular o interesse, e isso significa conceder autoridade às palavras, às coisas e às maneiras de fazer as coisas" (Masschelein \& Simons, 2017, p. 101).

\section{Dois Modos de Criar Igualdade de Oportunidades: o Mestre Ignorante e o Mestre Inventor}

A igualdade de oportunidade, nosso objeto de reflexão ao longo do texto, não se refere a buscar um modo de 'reduzir' as desigualdades existentes; afirmamos a necessidade de 'verificar' a igualdade, emancipando as diferentes inteligências. Como afirma Rancière (2011, pp. 11-12) não se trata de "[...] reduzir tanto quanto possível a desigualdade social, reduzindo a distância entre os ignorantes e o saber", mas trata-se de "[...] obrigar a quem quer que seja a verificar a igualdade de inteligências" (Ibidem). Para fazer essa verificação, é necessário compreender esse princípio e adotá-lo nas diferentes práticas escolares.

A escola deve promover a emancipação intelectual, a qual "[...] deveria devolver a cada um a igualdade que a ordem social the havia recusado e lhe recusaria sempre, por sua própria natureza" (Rancière, 2011, p. 15). Por isso, prestar atenção ao modo como se oferta os conhecimentos é tão importante para reconhecermos o princípio filosófico da igualdade de oportunidades que estamos destacando. Mais do que reconhecer esse princípio é necessário pensarmos os modos como os professores podem colocar em ação tal princípio.

Nesse sentido, nos propomos a apresentar alguns pressupostos defendidos por dois mestres do ensino: um europeu Joseph Jacotot (séc. XVIII e XIX), que nos é apresentado como o mestre ignorante por Jacques Rancière (2011). E, um mestre latino-americano - Simón Rodríguez (séc. XVIII e XIX), que nos é apresentado como o mestre inventor, por Walter Kohan (2015). Cada um deles busca, a seu modo, criar ou verificar as igualdades intelectuais de seus alunos. Por isso, vamos destacar alguns pontos de sua vida e de seus modos de fazer escola, como forma de analisar os modos possíveis de fazer uma escola com igualdade de oportunidade, para a inserção dos novos (estudantes) no mundo comum.

A experiência de Jacotot acontece no século XIX, quando lhe é permitido ensinar francês em uma universidade em Louvain (Bélgica), onde os alunos utilizavam-se apenas da língua holandesa para comunicação; seus alunos conheciam a língua holandesa e Jacotot, a francesa; ele ignorava saberes do holandês. Jacotot, no entanto, precisava encontrar 'algo comum', que servisse como disparador de curiosidade pela língua francesa em seus alunos. Em seu tempo fora publicada uma edição bilíngue (francês - holandês) do texto Telêmaco e, "[...] por meio de um intérprete, ele indicou a obra aos estudantes e lhes solicitou que aprendessem, amparados pela tradução, o texto francês" (Rancière, 2011, p. 18). Foi iniciada, portanto, uma experiência de aprendizado sem a presença do mestre explicador.

O mestre ignorante havia dado uma tarefa a seus alunos: aprender francês a partir da edição bilíngue de uma obra. Será que eles conseguiriam? Como deveriam fazê-lo? Jacotot apostou na capacidade intelectual de seus alunos, direcionando-os a um método de registro e repetição dos aprendizados e, desse modo, cada um, à sua maneira, poderia estabelecer relações com outros saberes. Assim, os alunos foram evoluindo no aprendizado da língua francesa e, “[...] qual não foi a sua surpresa, quando descobriu que seus alunos, abandonados a si mesmos, se haviam saído tão bem dessa difícil situação quanto o fariam muitos franceses" (Rancière, 2011, p. 18 - 19).

Jacotot é, pois, um mestre que "[...] se retira empiricamente do jogo e diz ao candidato à emancipação: o problema é seu, eis aqui esse livro, [...] observa os desenhos nessa página, diz o que podes reconhecer aí etc.” (Vermeren et al., 2003, p. 192). Ao mestre não importa saber as desigualdades presentes entre os diferentes sujeitos, ele deseja que todos e cada um aprendam a língua francesa. Ele acreditou nas capacidades intelectuais de seus alunos e nelas apostou para oportunizar um 
aprendizado, a partir da igualdade, para todos. A experiência não ocorreu sem dificuldades, mas a confiança do mestre e seu incentivo lhes despertou a vontade de retribuir àquilo que estavam recebendo.

Segundo Rancierè, havia nos alunos de Jacotot um desejo de aprender; eles 'queriam' dar resposta ao desafio que lhes foi proposto.

Todo o seu esforço, toda a sua exploração é tensionada pelo seguinte: uma palavra humana lhes foi dirigida, a qual querem reconhecer e à qual querem responder - não na qualidade de alunos, ou de sábios, mas na condição de homens, como se responde a alguém que vos fala, e não a quem vos examina: sob o signo de igualdade (Rancière, 2011, p. 29).

Muita coisa comum os unia, mas, principalmente, todos eram humanos em busca de reconhecerem-se uns aos outros através da língua, que até então não os unia. Esse é um pressuposto metodológico importante - reconhecer que todos nós somos humanos, que nos reconhecemos através da linguagem que usamos, que formamos comunidades educacionais e, por isso, podemos ser considerados iguais em oportunidades.

Esse modo de verificar a igualdade entre os alunos era "[...] antes de mais nada, um método de vontade. Podia-se aprender sozinho, e sem mestre explicador, quando se queria, pela tensão de seu próprio desejo ou pelas contingências da situação" (Rancière, 2011, p. 30). O mestre, nesse caso, adquire um status de emancipador, pois ele deixa de ser um 'dominador' de saberes (mestre explicador) e passa a desafiar seus alunos a buscar os conhecimentos necessários para sua vida e para o seu desenvolvimento.

O mestre, embora conduza um grupo de alunos, não é um instrutor de coletividades: “[...] ele só se dirige a quem se dirige a ele" (Vermeren et al., 2003, p. 195). A emancipação supõe um desejo, uma vontade de romper a naturalização das diferenças. Se não houver o desejo de ser emancipado, as possibilidades de esse método dar certo são mínimas. Por isso, o papel do professor como um incentivador, como alguém que deposita confiança nos alunos pode constituir neles o desejo por emancipar-se, por romper as barreiras que legitimam a desigualdade das inteligências.

É importante destacar que os alunos "[...] haviam aprendido sem mestre explicador, mas não sem mestre" (Rancière, 2011, p. 31), pois o mestre ignorante "[...] havia sido mestre por força da ordem que mergulhara os alunos no círculo de onde podiam sair sozinhos, quando retirava a sua inteligência para deixar a deles entregues àquela do livro" (Ibidem). Isso significa ‘confiar' nas capacidades intelectuais de cada aluno e ‘forçá-los' a usar sua própria inteligência. Além disso, é necessário/possível que o professor interrogue e verifique o trabalho da inteligência dos alunos, para dessa forma corrigir possíveis erros ou distorções no aprendizado.

Cabe, então, aos professores emancipadores “[...] fornecer, não a chave do saber, mas a consciência daquilo que pode uma inteligência, quando ela se considera como igual a qualquer outra como igual a sua" (Rancière, 2011, p. 64). Esse pode ser outro pressuposto para reconhecer quando a escola oportuniza aprendizados: considerar que o aluno possui inteligência, que pode ser diferente entre as pessoas, e pode, a essas inteligências associarem todos os elementos que compõem ou passam a compor seu contexto.

Poderíamos continuar apontando outros pressupostos das maneiras 'ignorantes' de propor igualdade na escola, no entanto, nos estenderíamos demais. Com o que tratamos sobre o mestre ignorante destacamos quatro elementos: o mestre precisa (1)'desafiar' seus alunos a buscar o conhecimento; isso gera (2) 'desejos' de aprendizagem; dessa forma, eles não receberiam tudo pronto do mestre explicador. Para tanto, é necessário, primeiro, promover um ambiente de (3) 'confiança' nas capacidades dos alunos, desenvolvendo, na mesma direção, (4) ‘crença’ na inteligência dos alunos.

Do outro lado do Oceano Atlântico, mais precisamente na América Latina, encontramos o mestre inventor - um viajante educador. Trata-se da experiência de vida de Simón Rodríguez, transcorrida entre os séculos XVIII e XIX. Em sua história o que mais se destaca são suas viagens e a construção de escolas por onde passava. O que faremos, pois, é reflexão sobre algumas de 
suas características, sustentadas sobre o pressuposto da igualdade de oportunidades dos alunos. Walter Kohan (2015, p.13) nos diz, sobre Rodríguez, que “[...] seu destino é inventar, sua vocação é ensaiar e errar, seu desafio é o atrever-se sempre a inventar, apesar do errar e do fracassar". É no intuito de perceber a docência como um ensaiar-se em busca de promover a emancipação intelectual dos alunos que apresentamos nossa reflexão abaixo.

Kohan (2015) destaca um episódio marcante, disparador de pensamentos diferentes na vida do mestre inventor. Tratase de um episódio onde um menino "[...] menor, o negro, o estranho - estrangeiro no grupo" (Kohan, 2015, p. 33) chamado Thomas, dá uma ideia ao grupo de Rodríguez para resolver um problema. Thomas inventou e utilizou-se de dois saberes que possuía e ajudou o grupo a resolver o que precisava. No entanto, o menino não era aluno de Rodríguez e, muito menos aluno de alguma escola; vivia num tempo em que a escola era para poucos. Surpreso com o que havia acontecido e incomodado pela situação de Thomas que não frequentava a escola, o mestre inventor começa a pensar que a escola não pode continuar fechando as portas para meninos como ele.

Simón Rodríguez acreditava que era necessário "[...] criar condições para que pequenos como o Thomas possam criar e recriar suas vidas e a de todos, e não como na sociedade colonial em que devem se submeter a um modo de vida que não deles" (Kohan, 2015, p. 34). As escolas existentes na sua época e as repartições públicas que as organizavam precisariam levar essas pessoas em consideração ao pensar e colocar em ação suas propostas. Mais do que isso, "[...] é preciso que todas as crianças - e não somente o Thomas - possam se tornar o que são" (idem), assim cada criança poderia desenvolver sua subjetividade, sua inteligência e teria iguais oportunidades de aprimoramento e de inserção no mundo.

Esse acontecimento mostra ao mestre inventor que é necessário pensar o mundo de outra forma, ver os alunos com outros olhos, perceber o mundo a sua volta com outra sensibilidade. É preciso "“...] estar no mundo diferente, um pensar de outra maneira, um praticar outras formas de vida social, uma nova escola de vida" (Kohan, 2015, p. 47).

O mestre inventor foi um professor que inventou escolas, nas quais ele mesmo vivia e ensinava. Essas escolas, eram de outra ordem; elas rompiam com os paradigmas dominantes da época. Segundo Kohan (2017, p. 598) Rodríguez suspende a "ordem honorífica e tradicional da sociedade monárquica, segundo a qual as crianças frequentavam uma escola em função da casta à qual pertenciam, e cria uma escola, sem condições, em pé de igualdade, para todas as crianças, para além de sua cor de pele, casta, pertença cultural, sexo ou religião". Na escola de Rodríguez se suspendem os privilégios, se abolem as diferenças ditas 'naturais', que separam os que são mais bem posicionados financeiramente (e, por conseguinte, seriam mais inteligentes) daqueles mais pobres (que seriam menos inteligentes). É uma escola que considera a igualdade potencial de inteligência de todos e todas, na qual meninos e meninas poderiam estudar, inventar, criar, aprender e se posicionar diante das coisas do mundo.

Em suas viagens pelo mundo o que mais Rodríguez fez, segundo Kohan (2015, p. 48), foi dedicar-se às letras. Ele, “[...] acima de tudo, estuda, nos livros e na vida. [...] os mais altos ensinamentos estão nos livros. No fim das contas são as letras, as obras, e não os modos de vida, o que o velho mundo tem oferecido de melhor" (Ibdem). Assim, as tradições e os conhecimentos construídos em outros momentos da história se revelavam importantes em sua vida. Ele tomava essas leituras como um modo de experienciar-se através dos saberes que ia adquirindo; isso possibilitava que ele cada vez mais percebesse o mundo de outras formas. Pelos seus estudos o mestre inventor, “[...] cria seus próprios métodos de ensino. Sempre assim: viaja, aprende, ensina” (Kohan, 2015, P. 50).

Acreditamos que o grande ensinamento proposto pelo mestre inventor é que pensemos o processo de ensinar e aprender como um movimento, como uma viagem, pois afinal “[...] para aprender e ensinar é importante estar atento, mas também estar atento em movimento" (Kohan, 2015, p. 59). Essa 'viagem' em busca do aprender e do ensinar é um percurso criterioso; é preciso olhar para os detalhes, para os pequenos gestos daqueles que nos cercam, que constroem o nosso cotidiano, para as surpresas que podemos ter com aqueles que se aproximam. Dessa forma, o ensino é um caminho “[...] entre dois pontos, o de partida e o 
de chegada, os dois igualmente insatisfatórios, quase insuportáveis, como lugares de residência para alguém tão inquieto" (idem). O que acontece, 'no caminho', pode ser a revelação das igualdades de oportunidades para os alunos.

\section{Considerações Finais}

Pensar a escola como um espaço de geração de oportunidade para todos, requer que rompamos com alguns paradigmas que operam no imaginário social e educacional: para aluno pobre se deve oferecer menos oportunidades de conhecimentos, afinal nunca saíram de seu mundo de pobreza; a escola deve 'direcionar' para profissões. No entanto, consideramos importante desnaturalizar as premissas: que todos os conhecimentos precisam ter uma utilidade e que todos os alunos aprendem de forma igual, pois todos estão tendo o conteúdo desenvolvido através de um único professor e seu método.

O modo de Jacotot desenvolver suas aulas e incentivar os alunos a aprenderem francês foi, sem dúvidas, desafiante e, também desconcertante para outros professores da mesma universidade. A escola inventada por Rodríguez em Chuquisaca "[...] foi demolida pelos que a consideravam uma ameaça à ordem imperante" (Kohan, 2017, p. 603). No entanto, nem Jacotot e nem Rodríguez se desanimaram, continuaram: Jacotot desejando ensinar outras coisas que ignorava e Rodríguez viajando, construindo e inventando outros modos de ser escola com igualdade. Isso nos mostra que, mesmo diante das inúmeras dificuldades, não podemos nos entregar e deixar de inventar.

Por isso, consideramos fundamental que os princípios da igualdade de inteligências e o do 'todos são capazes de...' devem sustentar nossa teoria educacional e nossa prática docente. O professor precisa continuar sua busca pelo conhecimento, em prol do desejo de mudança, comprometendo-se com a vida dos alunos que está em suas mãos. Isso não é tarefa fácil, sabemos bem. Por fim, consideramos que "[...] a educação é o ponto em que decidimos se amamos o mundo o bastante para assumirmos a responsabilidade por ele e, com tal gesto, salvá-lo da ruína que seria inevitável não fosse a renovação e a vinda dos novos e dos jovens" (Arendt, 2007, p. 245).

Fortalecer o escolar e assumir o princípio da igualdade das inteligências continua sendo a tarefa nossa tarefa como professores. Ao fazer isso se abre a possibilidade dos sujeitos educacionais perceberem que há "um mundo fora de seu próprio mundo da vida" (Masschelein \& Simons, 2017, p. 171), e que através dos conhecimentos há outras maneiras possíveis de se reinventar como sujeito habitante de uma sociedade.

\section{Referências}

Arendt, H. (2007). Entre o passado e o futuro. Perspectiva.

Arendt, H. (2008). A condição humana. Forense Universitária.

Biesta, G. (2013). Para além da aprendizagem: educação democrática para um futuro humano. Autêntica Editora.

Caridade, N. V. D. (2021) Processo escolar no ensino fundamental de um aluno surdo em uma escola de Macapá, Amapá. Pesquisa, Sociedade e Desenvolvimento 9 (3), 1- 10. 10.33448/rsd-v9i3.2722

Carvalho, J. S. F. de. (2020) Do Mestre Ignorante ao Iniciador: forma escolar e emancipação intelectual. Outros Temas - Educação e Realidade. 45 (2), 1-13. https://doi.org/10.1590/2175-623691817

Cruz, L. G., \& Agudo, M. de M. (2018). O histórico da escola pública moderna, sua configuração contemporânea e sua função social. Roteiro. 43 (esp), 77 100. https://doi.org/10.18593/r.v43iesp.16337

Cruz, C. S., \& Bretas, S. A. (2021) O método da igualdade: Jacotot e a experiência do ensino universal no contexto da Revolução Francesa. Cadernos de História da Educação. 20, 1-14. https://doi.org/10.14393/che-v20-2021-22

Durán, M. L. (2018) Simón Rodríguez y la escucha al borde del vacío: lecturas en clave ontológica de la escuela. Pro-posições. 29 (2), 299-321. https://doi.org/10.1590/1980-6248-2016-0007

Estrela, C. (2018). Metodologia Científica: Ciência, Ensino, Pesquisa. Editora Artes Médicas.

Khan, A. (Diretor). (2007). Como estrelas na Terra [Filme]. Walt Disney Home Entertainment. 
Research, Society and Development, v. 10, n. 11, e402101119856, 2021

(CC BY 4.0) | ISSN 2525-3409 | DOI: http://dx.doi.org/10.33448/rsd-v10i11.19856

Kohan, W. O. (2015). O mestre inventor: relatos de um viajante educador. Autêntica Editora.

Kohan, W. O. (2017). Entre nós, em defesa de uma escola. Revista de educação Temática Digital. 19 (4), 590 - 606. https://doi.org/10.20396/etd.v19i4.8648631

Kohan, W. O. (2019). Paulo Freire e o valor da igualdade em educação. Educação e Pesquisa. 45, 1-19. https://doi.org/10.1590/S1678-4634201945201600

LaGravenese, R. (Diretor). (2007). Escritores da Liberdade [Filme]. MTV Films.

Masschelein, J., \& Simons, M. (2017). Em defesa da escola: uma questão pública. Autêntica Editora.

Suédson, S. R., \& Neto, J. T. (2021) O mestre ignorante de Jacques Rancière: um caminho para a aprendizagem da filosofia no ensino médio. Revista Dialectus. 20, 133 - 153. https://doi.org/10.30611/2020n20id62612

Raagi, D. G. (2019) A experiência de Jacotot: contribuições para a formação emancipatória do trabalhador. Argumentum. 11 (3), 157 - 170. https://doi.org/10.18315/argumentum.v11i3.24473

Rancière, J. (2011). O mestre ignorante: cinco lições sobre a emancipação intelectual. Autêntica Editora.

Rigue, F. M, Oliari, G., Sturza, R. B., Tomazzeti, E. M., \& Veiga, A. M. da R (2020). Professor amador: contrastantes possibilidades com a formação de professores no Brasil. Pesquisa, Sociedade e Desenvolvimento. 9 (2), 1-17.. 10.33448/rsd-v9i2.2000

Santos, K. A. Dos. (2018). O pensamento pedagógico de Simón Rodríguez: por uma educação pública e popular. Revista Educação e Emancipação. 11 (3), 142 - 158. http://dx.doi.org/10.18764/2358-4319.v11n3p142-158

Vermeren, P., Cornu, L., \& Benvenuto, A. (2003). A atualidade de O mestre ignorante. Revista Educação e Sociedade. 24 (82), 185 - 202. https://doi.org/10.1590/S0101-73302003000100009 